\title{
Axis Screw Fixation - A Step-by-Step Review of the Surgical Techniques
}

\section{Fixação do áxis com parafusos - uma revisão passo a passo das técnicas cirúrgicas}

\author{
Andrei F. Joaquim ${ }^{1} \quad$ K. Daniel Riew ${ }^{2}$ \\ ${ }^{1}$ Department of Neurology, Discipline of Neurosurgery, Universidade \\ Estadual de Campinas (UNICAMP), Campinas, SP, Brazil \\ 2 Department of Orthopedics, Columbia University, New York, NY, \\ United States \\ Address for correspondence Andrei Fernandes Joaquim, MD, PhD, \\ Departamento de Neurologia, Universidade Estadual de Campinas, \\ Rua: Tessália Vieira de Camargo, 126, Cidade Universitária, \\ 13083-887, Campinas, SP, Brazil (e-mail: andjoaquim@yahoo.com).
}

Arq Bras Neurocir 2017;36:101-107.
Abstract
Keywords
- axis
- screw
- lamina
- pars
- pedicle
- transarticular

In this article, we present the techniques of axis screw fixation (laminar, pars, pedicle and transarticular screws), discussing the indications and contraindications of each one, as well as surgical tips and anatomical landmarks.

\section{Resumo \\ Palavras-chave \\ - áxis \\ - parafuso \\ - lâmina \\ - pars \\ - pedículo \\ - transarticular}

No presente artigo, apresentamos as técnicas de fixação do áxis com parafusos (lamina, parafusos de pars, pedículo e transarticular), discutindos as indicações e contraindicações das mesmas, assim como dicas cirúrgicas e parâmetros anatômicos relevantes.

\section{Introduction}

Fixation of the axis may be necessary in cases of atlantoaxial instability, secondary to different causes, such as congenital, trauma, neoplasm or inflammatory diseases. ${ }^{1}$ Additionally, the axis may be included in the spinal instrumentation procedure requiring occipitocervical stabilization or even extension of the subaxial cervical spine surgeries. ${ }^{1}$ The classic fixation of the atlantoaxial region, based on wiring techniques, such as those described by Brooks-Jenkis, Sonntag, Gallie, and their variations, were associated with a high rate of nonunion (up to $30 \%$ of the patients), and the need of wearing a postoperative cervical brace (such as a rigid cervical collar or a halo-vest) because of their limited ability to restrict C1-2 motion properly. ${ }^{2-5}$ Due to these limitations, modern fixation of the axis is mainly based on more rigid constructions, based on instrumentation of the axis using polyaxial screws. ${ }^{1,6}$ received

December 12, 2016 accepted after revision January 27, 2017 published online March 31, 2017

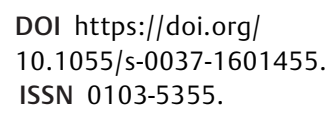

Copyright $@ 2017$ by Thieme Revinter

Publicações Ltda, Rio de Janeiro, Brazil

License terms

(c) (i) $\ominus$ (\$) 
Screw-based constructs at C2 have higher rates of fusion and immediate stability, being much more efficient in restricting motion of the atlantoaxial joint than wiring techniques. The most commonly used screw-based fixation techniques of the axis are: laminar, pedicular, pars interarticularis and transarticular C1-2 screws.

In this article, we described these four screw techniques used to stabilize the axis, discussing indications and contraindications of each one, as well as surgical tips and anatomical landmarks.

\section{Basic Surgical Anatomy of the Axis}

The axis has a large vertebral body that contains the odontoid process, also known as dens. ${ }^{7}$ The odontoid articulates with the anterior arch of the atlas, held in place by the transverse ligament. The axis also has two pars interarticularis (also known as isthmus), two pedicles, the laminae and bilateral transverse processes (-Fig. 1). ${ }^{7}$ According to Ebrahein et al, the pedicle of the axis must be defined as the portion that goes from beneath the superior facet and the anteromedial region to the transverse foramen, whereas the pars interarticularis is the portion between the inferior and the superior facets (-Fig. 1) ${ }^{7}$

\section{C2 Laminar Screw Fixation}

\section{General Considerations}

The first report of laminar screw fixation of the axis is recent, published in 2004 by Wright et al. ${ }^{8}$ This technique was considered to be an alternative form of fixation for the $~$ $20 \%$ of patients who have anatomic anomalies that preclude the safe use of transarticular C1-2 screw or pedicular screw fixation due to the risk of vertebral artery injury. 9,10

This technique is generally made without using intraoperative fluoroscopy (free hand technique) and does pose a risk to the vertebral artery. Successful treatment of craniocervical fusions, atlantoaxial fixation and axis inclusion in subaxial fixation has been extensively reported in the literature. ${ }^{11,12}$ However, if a laminectomy of the axis is necessary for decompressing the spinal cord, obviously C2 laminar screws cannot be used. ${ }^{1}$ Additionally, it has the disadvantage of the need to use head screw extension connectors in some cases, since the rods are generally far from the screw head, due to the oblique orientation of the laminar screws compared with subaxial cervical lateral mass screws.

Considering the dimensions of the axis for laminar screw placement, Cassinelli et al evaluated 420 adult specimens of

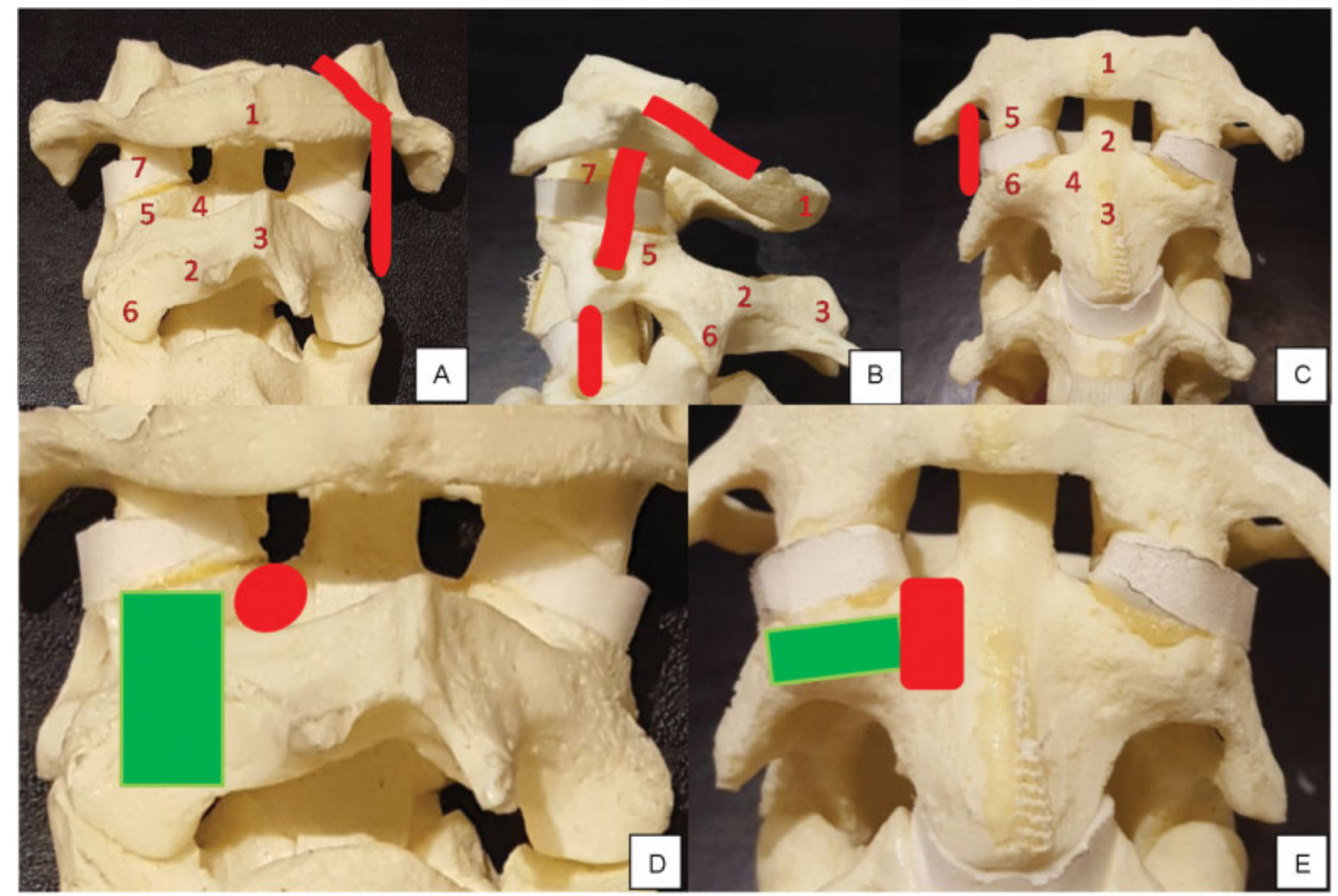

Fig. 1 (A) Posterior view of C1-2-3. 1-Posterior tubercle of C1; 2-Lamina of C2; 3-Spinous process of C2; 4- pedicle of C2; 5-Superior facet joint of C2; 6-Inferior facet joint of C2; 7- Lateral mass of C1. The vertebral artery is illustrated. (B) Lateral View of C1-2-3. 1-Posterior tubercle of C1; 2Lamina of C2; 3- Spinous process of C2; 4- pedicle of C2; 5- Superior facet joint of C2; 6- Inferior facet joint of C2; 7- Lateral mass of C1. The vertebral artery is illustrated. (C) Anterior View of C1-2-3. 1- Anterior tubercle of C1; 2-Dens; 3-Body of the axis; 4-Pedicle of C2; 5- Lateral Mass of $C 1$; 6-Superior facet joint of C2. The vertebral artery is illustrated. (D) Posterior view of C2 - the green area represents the region of the pars interarticularis (the area of $\mathrm{C} 2$ vertebra that connects the superior and the inferior facet joint) and the red area represents the pedicle, a bone bridge of $\mathrm{C} 2$ that connects the vertebral body with the posterior elements). (E) Anterior view of $C 2$ - the green area represents the region of the pars interarticularis and the red area the pedicle of the axis. 
$\mathrm{C} 2$, and reported that the mean laminar thickness was $5.77 \pm$ $1.31 \mathrm{~mm} .^{13}$ In $70.6 \%$ of the specimens, the laminar thickness was $\geq 5 \mathrm{~mm}$ and in $92.6 \%$ of them thickness was $\geq 4.0 \mathrm{~mm}$. Considering screw length, the mean feasible screw length of the studied sample was $24.6 \pm 0.23 \mathrm{~cm}$, and more than $99 \%$ of the specimens could receive an estimated screw length of at least $20 \mathrm{~mm}$. This study suggested that this technique can be used in the vast majority of adult patients. In pediatric patients, a computerized tomography (CT) based study of 75 children of ages 2 to 10 years ( 24 to 120 months old), all of them had a lamina thickness $>3.5 \mathrm{~mm}$ and only $1.2 \%$ of the axis pedicles were less than $3.5 \mathrm{~mm}$ thick. ${ }^{14}$ The length of the lamina and the pedicle was $\geq 12 \mathrm{~mm}$ in all cases. This anatomical study, as well as many clinical reports, suggests that laminar screws can be safety used in pediatric patients requiring $\mathrm{C} 2$ screw fixation. ${ }^{11,13,14}$

\section{Surgical Technique}

The patient is positioned prone with the head resting in a head holder with neutral neck position (military tuck). 1,15,16 A midline incision is made in the posterior cervical spine, just below the inion level to the cervical spine. A meticulous subperiosteal dissection is required, as well as exposure of the posterior arch of $\mathrm{C} 1$, of the spinous process, the lateral masses and the lamina of the axis. The junction of the spinous process and lamina is the entry point. On one side, a small cortical hole is performed with high speed drill in the upper portion of the spinous process-lamina junction. For example, an upper hole in the spinous process-lamina junction of the right side is made for a left laminar screw. A hand drill is used to guide the trajectory of the screw, based on preoperative CT scan study of the length of the lamina, aligned with long axis of the contra lateral lamina directed to the laminar surface, but not too much to avoid cortical breakthrough into the spinal canal. If the dorsal lamina is perforated, there is no problem. In fact, in osteoporotic individuals, perforation of the dorsal cortex insures a bicortical screw with a stronger purchase than a purely intra-laminar screw. A small ball probe is then used to make sure that there was no spinal canal violation. The screw inserted is generally 3.5 to $4 \mathrm{~mm}$. On the other side, another hole is performed in the spinous process-lamina junction, but in its inferior portion, in order to avoid crossing both screws at the midline. The same trajectory is made on the other side, directing the long axis of the lamina with a hand drill, followed by a ball probe to palpate the bone trajectory and then screw insertion.

A Penfield dissector may help to palpate the inner portion of the lamina that may help directing the hand drill prior to screw insertion.

\section{C2 Pars Interarticularis Screw and C2 Transarticular Screw}

\section{General Considerations}

The trajectory of $\mathrm{C} 2$ pars screws and the entry point are exactly the same of transarticular screws, but the latter cross the superior portion of facet joint of C2 directly to the center of $\mathrm{C} 1$ lateral mass, having a greater length (average 20 to 30 $\mathrm{mm}$ ) compared with pars screws (average 12 to $18 \mathrm{~mm}$ ). ${ }^{17}$ Although commonly mistaken, one has to understand the difference between pars and pedicle screws. Understanding the starting points and trajectories of the two screws is mandatory to identify the best one for any given patient.

In a study of $50 \mathrm{CT}$ scans of adults, Hoh et al reported that almost $99 \%$ of them were able to receive $14 \mathrm{~mm}$ length pars screws, which may provide good fixation. ${ }^{12}$

\section{Surgical Technique}

The patient is positioned prone with the head fixed in a head holder with neutral neck position. ${ }^{1,15,16}$ A gauze roll is placed in the patient mouth after intubation to allow anteroposterior fluoroscopy if transarticular screws placement is planned, according to the surgeon's preferences. A midline incision is made in the posterior cervical spine, just below the inion level to the subaxial cervical spine. It is mandatory to perform a meticulous subperiosteal dissection and exposure of the posterior arch of $\mathrm{C} 1$ and also the spinous process, lateral masses and lamina of the axis. The $\mathrm{C} 2-3$ joint is minimally exposed. The entry point is found $\sim 3$ to $5 \mathrm{~mm}$ above the $\mathrm{C} 2-3$ junction, as medial as possible but without violating the spinal canal and the medial portion of the pars. ${ }^{17-19}$ For pars screw technique, after performing a small hole with a drill, a hand drill is made parallel to the pars interarticularis in a lateral fluoroscopy (generally, great craniocaudal inclination is required for maintaining a parallel trajectory to the pars). It is important to evaluate the foramen transversum: most of the times, they are just anterior to the posterior vertebral line. Then, a hand drill or a pedicle probe is carefully used. The more vertical the trajectory, the greater the risk to the vertebral artery. One can continue till the drill reaches the posterior vertebral line on fluoroscopy to avoid injury to the vertebral artery. After hand drilling, the ball probe is inserted into the pars to check any cortical violation and, if there was no violation, the pars screw is inserted. For transarticular screws, it is mandatory to check the size of the pars of the axis. Sciubba et al reported that the size of the pars of C2 may be evaluated using a parasagittal CT scan reconstruction - if the entire pars of $\mathrm{C} 2$ can be visualized on a single image slice, then a transarticular screw can be safely inserted. Since the average CT image cuts are $3 \mathrm{~mm}$, if it can be visualized on at least 2 cuts, the pedicle is likely to be greater than $3 \mathrm{~mm}$ wide. Failure to identify an anomalous medially located vertebral artery may result in catastrophic injury. The medial and superior edges of the $\mathrm{C} 2$ pedicle are palpated to avoid breaking the cortical bone. Removal of the C1-2 articular cartilage is recommended to improve fusion rates, especially if iliac crest autograft is not utilized. A threaded guide pin is preferentially used, estimating the skin entry point lateral to the neck with lateral fluoroscopy in the trajectory of the screw throughout the pars and into the lateral mass of $\mathrm{C} 1$. If necessary, an auxiliary lateral stab incision is performed, at approximately the T2-4 area. Therefore, the skin must be prepped out to the mid-thoracic spine. This additional incision minimizes the length of the main midline skin incision, especially when only atlantoaxial fusion is planned (not including the subaxial cervical spine). The trajectory of the pin guide is directed toward the center of the atlas lateral mass (on anteroposterior 
view) and toward the anterior arch (on lateral view). The pins are then measured for proper screw length selection. When inserting a cannulated screw, it is necessary to make sure that there is a good C1-2 alignment, without any distraction at the C1-2 joints (axial support in the vertex of the head may be performed by the auxiliary surgeon to avoid joint distraction). If an auxiliary stab incision was used, the screwdriver should be passed percutaneous and then the screw must be locked to the screwdriver near the screw entry point, to avoid losing it in the paraspinous muscles. Also, frequent fluoroscopic images should be obtained to make sure that the guide wire is not advanced during the drilling and screwing, as one can inadvertently advance it into the cranium. After bilateral screw insertion, the lamina of the axis and the posterior arch of the atlas are decorticated for receiving bone graft. A supplemented wiring technique in the posterior arch of $\mathrm{C} 1$ and the lamina of C2 may be performed to improve fusion rates at surgeon's discretion. ${ }^{17,18}$

\section{Attention}

- total reduction of the $\mathrm{C} 1-2$ joint is necessary for transarticular screw placement. Preoperative traction may be used for reduction. In cases where total reduction is not possible, lateral mass screw fixation of the atlas should be performed, with another isolated C2 screw fixation technique (pedicle, pars or lamina screws). One can also reduce the joint intraoperatively using cables under $\mathrm{C} 1$ and around $\mathrm{C} 2$.

- checking the vertebral artery position on preoperative CT scan is mandatory: a medially located vertebral artery is a formal contraindication for transarticular screws.

- biplanar fluoroscopy is strongly recommended for transarticular screws: poor visualization may increase the likelihood of a malpositioned screw.

- excessive cranial angulation may result in violation of the condyle-C1 joint; an inferior trajectory may result in inadequate fixation of the $\mathrm{C} 1$ lateral mass; a too medial trajectory results in injury to the spinal cord and too lateral trajectory results in additional risk of vertebral artery injury.

- if one vertebral artery is injured, the surgeon should not insert a contra lateral screw, since bilateral vertebral injury may result in death or catastrophic stroke. ${ }^{17,18}$

\section{C2 Pedicle Screw}

\section{General Considerations}

The pedicle is the region connecting the C2 vertebral body with the posterior elements of the axis and a true pedicle screw passes obliquely to the pedicle, toward the body of the axis. The first description of the $\mathrm{C} 2$ transpedicular screw was probably made by Robert Judet, in France, in 1962.

\section{Surgical Technique}

Positioning and exposure are identical to the pars screw, described above. Since a pedicle screw starting point is more rostral, the $\mathrm{C} 2-3$ joint does not need to be exposed. The entry point is found in the transition between the lateral portions of the lateral mass of $\mathrm{C} 2$, a little inferior $(\sim 2 \mathrm{~mm})$ to the transition of the lateral mass-pars. If one draws an imaginary line extending the rostral border of the C2 lamina, this is a good starting point in the cranial-caudal direction. This is a high and lateral entry point, potentially minimizing the risk of vertebral artery injury. With a dissector, the medial and rostral portions of the pedicle of $\mathrm{C} 2$ are palpated, guiding the trajectory of the handing drill. The medial and rostral cortical bone of the pedicle should not be violated. Canal penetration occurs with a medial violation and vertebral artery injury can occur with a lateral violation. The caudal-rostral trajectory is parallel to the slope of the $\mathrm{C} 2$ pars, or may be guided by lateral cervical fluoroscopy, directed toward C2 body. ${ }^{20}$ After drilling, a ball-tipped probe is used to make sure that there was no cortical violation or excessive bleeding, and proper screw length is measured and inserted. Generally, venous bleeding suggests transverse foramen violation, and arterial bleeding suggests vertebral artery injury.

\section{Attention}

- similarly to transarticular screws, assessment of the width of the $\mathrm{C} 2$ pedicle is mandatory for transpedicular screws: the same rule is valid, as reported by Sciubba et al: if the entire pedicle of $\mathrm{C} 2$ can be visualized on a single image slice of a parasagittal CT scan, that means that the pedicle is greater than $3 \mathrm{~mm}$ wide and pedicle screws can be safely performed. ${ }^{20}$

- in fractures of the posterior elements of the axis, generally the fracture's line can be palpated with a Penfield dissector. Surgeons must be aware of this to avoid deviation of the screw direction.

- up to $20 \%$ of patients do not have pedicles of a sufficient size to receive a screw - in such cases, consider a pars screw, a laminar screw or wiring/hook techniques.

-Fig. 2 and 3 illustrate the differences among the screw techniques and an illustrative case is also presented in - Fig. 4.

\section{Final Considerations}

Biomechanical studies assessing insertional screw torque and pull-out strength reported that $\mathrm{C} 2$ pedicle screws may provide the strongest fixation, followed by laminar and, finally, by pars screws. ${ }^{21}$ However, further studies are necessary to validate the biomechanical studies in clinical context. In a large series of 167 patients, Parker et al evaluated the differences between $\mathrm{C} 2$ pedicle screws and C2 laminar screws (used when pedicle fixation presented potential anatomic risks). ${ }^{22}$ Grouping patients with upper (C1-2 or C1-2-3 fixation) and subaxial cervical spine fixation, they reported a higher rate of cortical violation with pedicle screws (11 cases, $7 \%$, none requiring surgical revision) than with laminar screws (2 cases, $1.3 \%, 1$ requiring a surgical revision $)(p=0.018)$. It is worth noting that the pseudoarthrosis rate was higher in the subaxial group receiving laminar fixation (4 patients were reoperated; 6.1\%) than in the pedicle screw group (no reoperation). All of the pseudoarthrosis occurred in the subaxial cervical spine group. They 


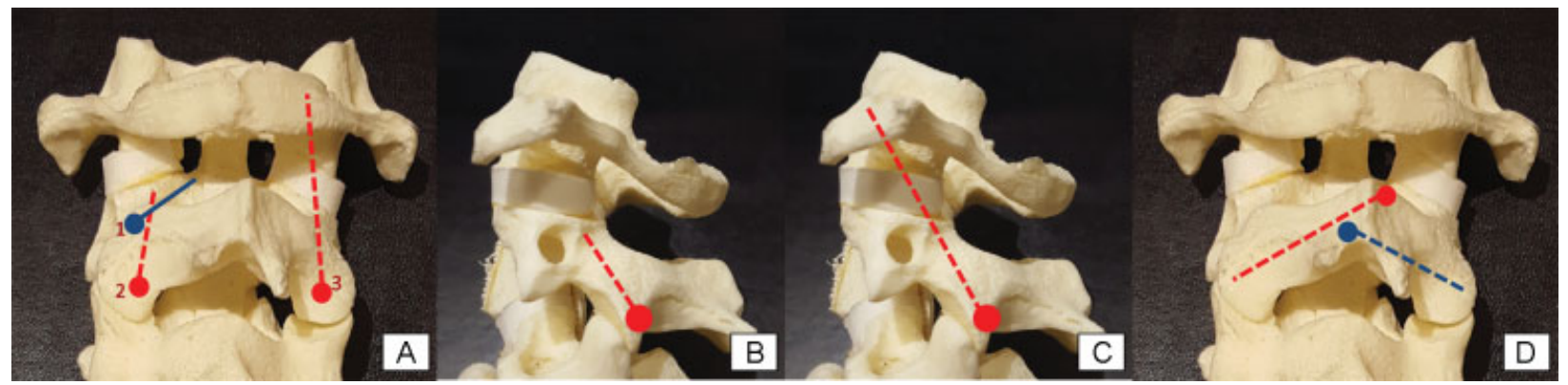

Fig. 2 (A) Posterior view of C1-2-3. 1- Illustrated perspective of the trajectory of the C2 pedicle screw and entry point: we start in line with the cranial edge of the $\mathrm{C} 2$ lamina and just lateral to the midpoint of the $\mathrm{C} 2$ pars; the more caudal the starting point, the harder it is to get into the pedicle and the easier it is to hit the artery. 2-Trajectory of the C2 pars screw and entry point, just superior and slightly lateral to the medial junction of the $\mathrm{C} 2-3$ joint ( $\sim 3$ to $5 \mathrm{~mm}$ above the junction, as medial as possible but without violating the spinal canal and the medial portion of the pars). 3- Trajectory of the C2 transarticular screw, with the same entry point of C2 pars screw. (B) Lateral View of C1-2-3. 1- Lateral perspective of the trajectory of the C2 pars screw. (C) Lateral View of C1-2-3. 1- Lateral perspective of the trajectory of the C2 transarticular screw. (D) Posterior view of C1-2-3. Illustrated perspective of the trajectory of bilateral C2 laminar screws and their respective entry points, in the junction of the lamina and the spinous process.

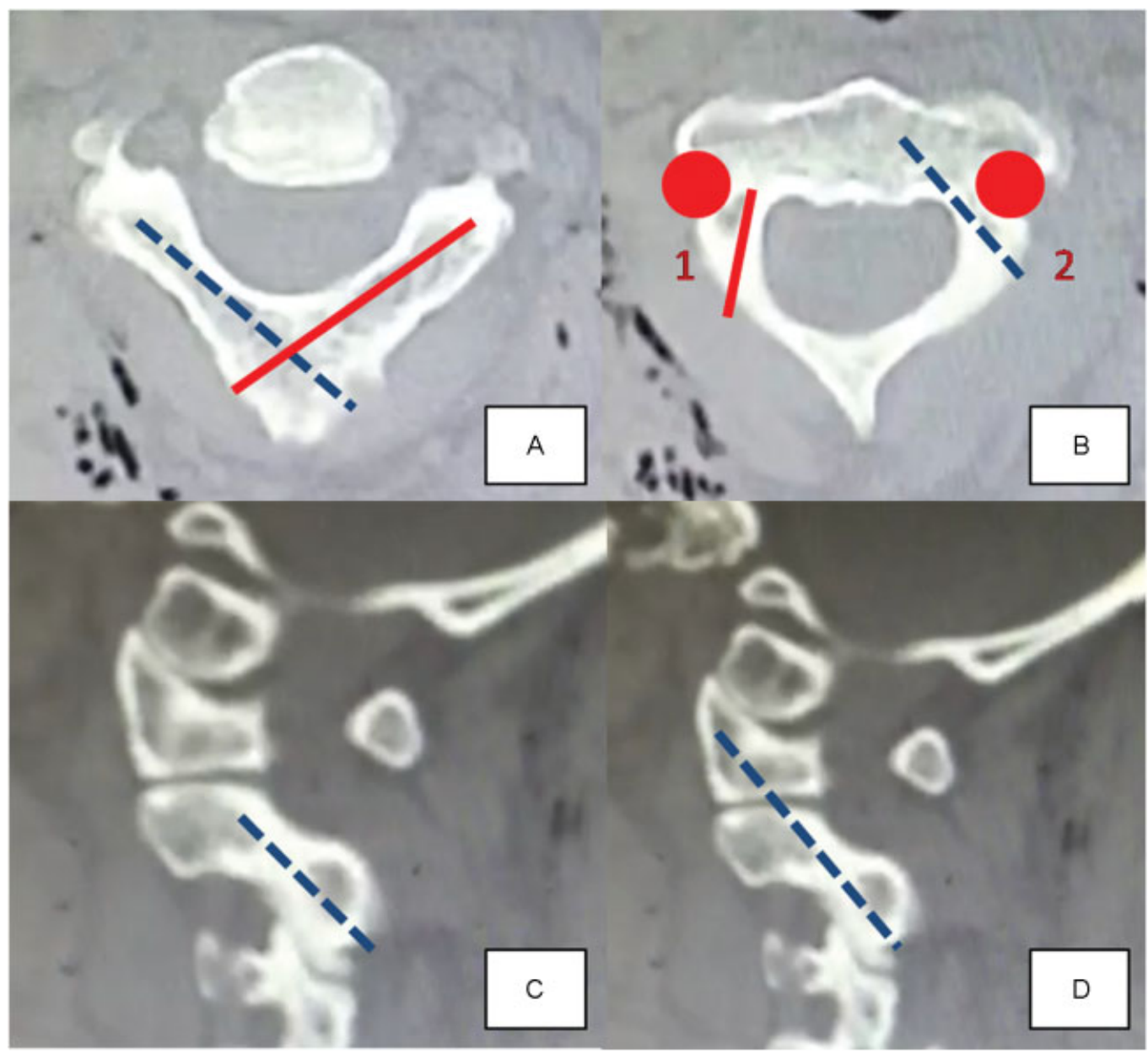

Fig. 3 Illustrative pictures of the screw trajectories based on CT scan. (A) Axial view of the C2 CT scan. Laminar screws are illustrated. (B) Axial view of the C2 CT scan. 1- Pars screw (right) and 2- Pedicle screw (left). The vertebral artery is illustrated. (C) Lateral view of the sagittal CT scan. The trajectory of the C2 pars screw is illustrated. (D) Lateral view of the sagittal CT scan. The trajectory of the C2 transarticular screw is illustrated. 


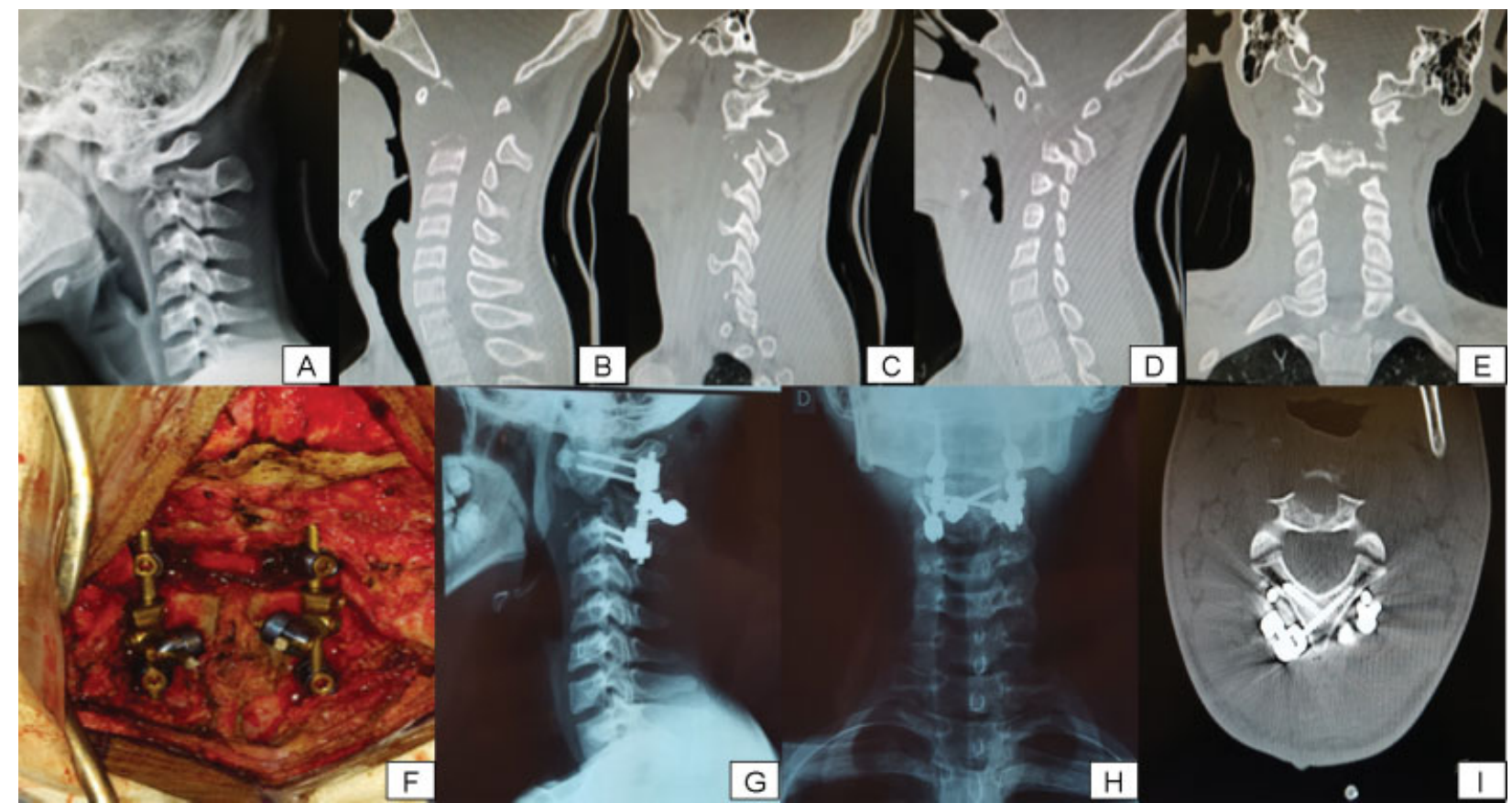

Fig. 4 Illustrative Case. (A) Lateral cervical X-ray shows destruction of the body of C2 (an osteolytic lesion, confirmed as a giant cell tumor after an anterior cervical biopsy), with anterior dislocation of the atlas over C2. (B, C and D) sagittal CT scan showing destruction of the dens, body, pars and pedicle of C2, precluding screw fixation on these structures. (E) Coronal CT scan and the lytic injury (F) Intraoperative view of C1 lateral masses screw fixation, bilateral laminar screws and C3 lateral masses screws. Note that connectors from the head of the C2 screws are used for attaching properly to the rods ( $\mathrm{G}$ and $\mathrm{H}$ ). Postoperative cervical X-rays (lateral and antero-posterior, respectively) with good alignment of the upper cervical spine. (I) Laminar screws in the axial CT scan.

concluded that using laminar screws in extension of subaxial cervical spine groups may increase the risk of pseudoarthrosis when compared with pedicle fixation. Regardless of the type of screw, a sufficient length of axis screw fixation provides rigid fixation with all the presented techniques.

Finally, spine surgeons should be familiar with all the screw techniques for fixating the axis, as well as their technical nuances, selecting the best option for each patient.

\section{Conflicts of interest}

No funds were received in support of this study. No benefits in any form have been or will be received from a commercial party related directly or indirectly to the subject of this manuscript. The authors have no financial interest in the subject of this article.

\section{Quiz - Additional Information for Residents (-supplementary material)}

\section{References}

1 Joaquim AF, Ghizoni E, Anderle DV, Oliveira Ed, Tedeschi H. Axis instrumentation: surgical results. Arq Neuropsiquiatr 2012; 70(11):857-863

2 Farey ID, Nadkarni S, Smith N. Modified Gallie technique versus transarticular screw fixation in C1-C2 fusion. Clin Orthop Relat Res 1999;(359):126-135
3 Dickman CA, Sonntag VK. Posterior C1-C2 transarticular screw fixation for atlantoaxial arthrodesis. Neurosurgery 1998;43(02): 275-280, discussion 280-281

4 Coyne TJ, Fehlings MG, Wallace MC, Bernstein M, Tator $\mathrm{CH}$. C1-C2 posterior cervical fusion: long-term evaluation of results and efficacy. Neurosurgery 1995;37(04):688-692, discussion 692-693

5 Rajinda P, Towiwat S, Chirappapha P. Comparison of outcomes after atlantoaxial fusion with $\mathrm{C} 1$ lateral mass-C2 pedicle screws and C1-C2 transarticular screws. Eur Spine J 2016 Oct 2

6 Jeanneret B, Magerl F. Primary posterior fusion C1/2 in odontoid fractures: indications, technique, and results of transarticular screw fixation. J Spinal Disord 1992;5(04):464-475

7 Ebrahein NA, Fow J, Xu R, Yeasting RA. The location of the pedicle and pars interarticularis in the axis. Spine 2001;26(04):34-37

8 Wright NM. Posterior C2 fixation using bilateral, crossing C2 laminar screws: case series and technical note. J Spinal Disord Tech 2004;17(02):158-162

9 Mandel IM, Kambach BJ, Petersilge CA, Johnstone B, Yoo JU. Morphologic considerations of $\mathrm{C} 2$ isthmus dimensions for the placement of transarticular screws. Spine 2000;25(12): 1542-1547

10 Igarashi T, Kikuchi S, Sato K, Kayama S, Otani K. Anatomic study of the axis for surgical planning of transarticular screw fixation. Clin Orthop Relat Res 2003;(408):162-166

11 Singh B, Cree A. Laminar screw fixation of the axis in the pediatric population: a series of eight patients. Spine J 2015;15(02): e17-e25

12 Hong JT, Yi JS, Kim JT, Ji C, Ryu KS, Park CK. Clinical and radiologic outcome of laminar screw at C2 and C7 for posterior instrumentation-review of 25 cases and comparison of $\mathrm{C} 2$ and $\mathrm{C} 7$ intralaminar screw fixation. World Neurosurg 2010;73(02):112-118, discussion e15 
13 Cassinelli EH, Lee M, Skalak A, Ahn NU, Wright NM. Anatomic considerations for the placement of C2 laminar screws. Spine 2006;31(24):2767-2771

14 Cristante AF, Torelli AG, Kohlmann RB, et al. Feasibility of intralaminar, lateral mass, or pedicle axis vertebra screws in children under 10 years of age: a tomographic study. Neurosurgery 2012;70(04):835-838, discussion 838-839

15 Joaquim AF, Ghizoni E, Rubino PA, et al. Lateral mass screw fixation of the atlas: surgical technique and anatomy. World Neurosurg 2010;74(2-3):359-362

16 Mudo ML, Amantéa AV, Cavalheiro S, Joaquim AF. Intraoperative radiological visualization of the occipito-cervical transition and upper cervical spine: technical note. Columna 2009;8:197-199

17 Yanni DS, Perin NI. Fixation of the axis. Neurosurgery 2010; 66(3, Suppl)147-152
18 Menendez JA, Wright NM. Techniques of posterior C1-C2 stabilization. Neurosurgery 2007;60(01, Suppl 1):S103-S111

19 Puschak TJ, Anderson PA. Posterior C1-C2 Transarticular Screws. Tech Orthop 2002;17(03):296-305

20 Sciubba DM, Noggle JC, Vellimana AK, et al. Radiographic and clinical evaluation of free-hand placement of $\mathrm{C}-2$ pedicle screws. Clinical article. J Neurosurg Spine 2009;11(01):15-22

21 Lehman RA Jr, Dmitriev AE, Helgeson MD, Sasso RC, Kuklo TR, Riew KD. Salvage of $\mathrm{C} 2$ pedicle and pars screws using the intralaminar technique: a biomechanical analysis. Spine 2008; 33(09):960-965

22 Parker SL, McGirt MJ, Garcés-Ambrossi GL, et al. Translaminar versus pedicle screw fixation of C2: comparison of surgical morbidity and accuracy of 313 consecutive screws. Neurosurgery 2009;64(05, Suppl 2):343-348, discussion 348-349 